\title{
Acute abdomen caused by ingested chicken wishbone: a case report Faton T Hoxha ${ }^{1}$, Shemsedin I Hashani ${ }^{1}$, Driton S Komoni ${ }^{1}$, Lumturije H Gashi-Luci ${ }^{2}$, Fisnik I Kurshumliu ${ }^{2}$, Medita SH Hashimi ${ }^{3}$ and Avdyl S Krasniqi*1
}

\author{
Address: ${ }^{1}$ Department of Abdominal Surgery, University Clinical Centre of Kosova, Prishtina, Republic of Kosovo, ${ }^{2}$ Institute of Pathology, \\ University Clinical Centre of Kosova, Prishtina, Republic of Kosovo and ${ }^{3}$ Department of Anesthesiology, University Clinical Centre of Kosova, \\ Prishtina, Republic of Kosovo \\ Email: Faton T Hoxha - faton_an@yahoo.com; Shemsedin I Hashani - shemihashani@gmail.com; \\ Driton S Komoni - dritonkomoni@hotmail.com; Lumturije H Gashi-Luci - lumaluci@hotmail.com; \\ Fisnik I Kurshumliu - fkurshumliu@yahoo.com; Medita SH Hashimi - meditah@yahoo.com; Avdyl S Krasniqi* - dr_krasniqi2001@yahoo.com \\ * Corresponding author
}

Published: 19 January 2009

Cases Journal 2009, 2:64 doi:10.1/86/1757-1626-2-64

This article is available from: http://www.casesjournal.com/content/2///64

(C) 2009 Hoxha et al; licensee BioMed Central Ltd.

This is an Open Access article distributed under the terms of the Creative Commons Attribution License (http://creativecommons.org/licenses/by/2.0), which permits unrestricted use, distribution, and reproduction in any medium, provided the original work is properly cited.
Received: 14 November 2008

Accepted: 19 January 2009

\begin{abstract}
Introduction: An ingested foreign body often passes the gastrointestinal tract without any complications. Foreign bodies, such as dentures, fish bones, chicken bones, and toothpicks, have been known to cause perforation of the Gl tract.

Case presentation: We are presenting a case of a fifty-year-old male with acute abdomen; diffuse fibro purulent peritonitis, i.e. ileum perforation, caused by accidentally ingesting a chicken wishbone. He was treated surgically with ileum resection, and temporary ileostomy. After four months, intestinal continuity was established in the second operation.

Conclusion: Intestinal perforation by a chicken bone is rare and affects the left colon or distal ileum. The lack of information of ingestion and detection of chicken bones preoperatively are of interest to be considered in the differential diagnosis of acute abdomen, which in this case was treated surgically.
\end{abstract}

\section{Introduction}

Ingesting a foreign body is not an uncommon occurrence and most foreign objects pass uninterrupted through the gastro intestinal tract without any complications [1]. In a few cases a patient's occurrence of bowel perforation leads to acute abdomen requiring surgical treatment $[1,2]$. Operative discovery remains in most cases [1]. Foreign bodies, such as dentures, fish bones, chicken bones, and toothpicks, have been known to cause perforation of the GI tract [1].

\section{Case presentation}

We are presenting a case with acute abdomen, i.e. ileum perforation, caused by accidentally ingesting a chicken wishbone.

A fifty-year-old male was presented in the surgical emergency clinic with abdominal pain, nausea, and vomiting. The symptoms had started two days earlier. He used tobacco, but denied having consumed alcohol. The patient's height was $170 \mathrm{~cm}$ and his weight was $120 \mathrm{~kg}$. His vital signs were: blood pressure $120 / 80 \mathrm{mmHg}$; pulse rate 90 beats/min.; respiration rate 19/min.; body temper- 
ature $38.5^{\circ} \mathrm{C}$. His past medical history consisted of surgery for a thrombophlebitis in his right arm one year earlier.

Upon physical examination, a distended and diffusely tender abdomen with right lower abdomen rebound was revealed. The patient's skin and mucosa were pale.

The emergent laboratory tests revealed as follow: white blood cells (WBC): $12.6 \times 10^{9} /$ liter; serum creatinine: 126 $\mathrm{mol} / \mathrm{L}$; blood urea nitrogen: $8.6 \mathrm{mmol} / \mathrm{L}$; blood sugar: $11.6 \mathrm{mmol} / \mathrm{L}$; Na: $141 \mathrm{mmol} / \mathrm{L} ; \mathrm{K}: 4.0 \mathrm{mmol} / \mathrm{L}$; Ca++: $1.08 \mathrm{mmol} / \mathrm{L}$; urinalysis: a lot of mucus, 4-6 Leucocytes; some epithelial cells. Plain abdominal radiography showed mechanical obstruction. Urgent abdominal ultrasound revealed mechanical obstruction, dilated small bowels and free liquid in the peritoneal cavity.

Laparotomy was performed in general anesthesia on the day the patient was admitted. Intra operative findings revealed diffuse fibro purulent peritonitis with adhesions between small bowels; and about $40 \mathrm{~cm}$ from Bauchini valve the presence of a sharp chicken wishbone perforated the ileum at the ante mesenteric site (Figure 1). The wall of that part of the ileum was thick and succulent. The patient was treated after the adhesiolisis with resection of

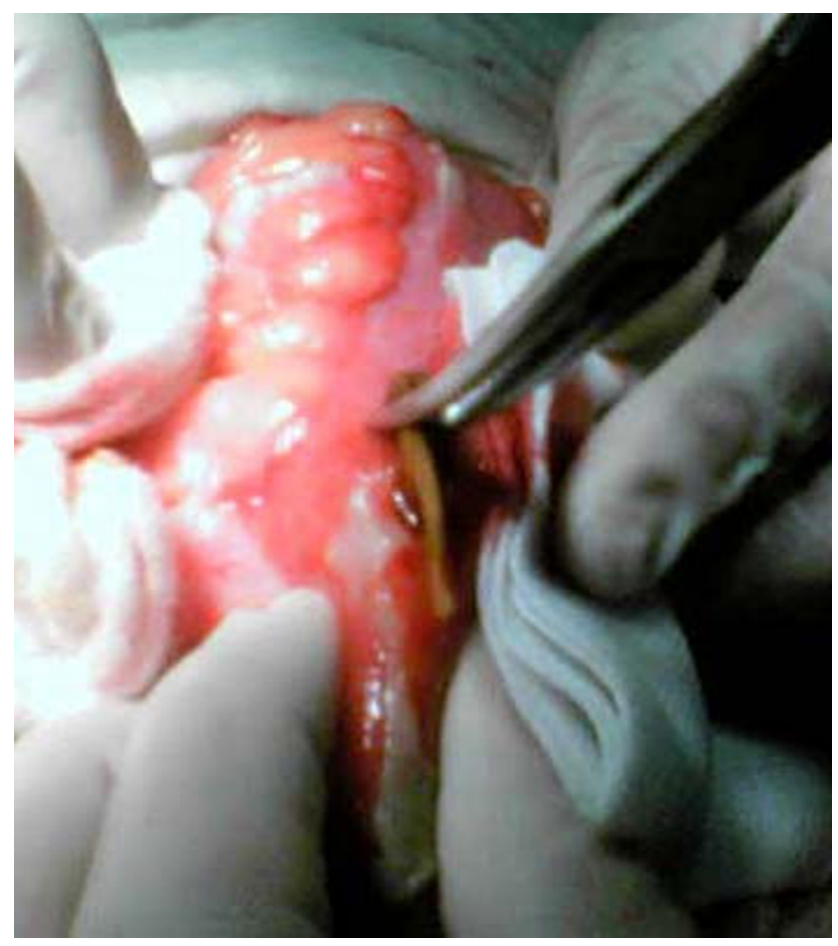

Figure I

Intra operative finding of perforated ileum with chicken wishbone. the perforated distal ileum and ileum stoma. The postoperative treatment went well; the wound healed per secundum. Clebsiela spp. was isolated in the stained abdominal liquid and treated with the proper antibiotics. Four months after the first operation and losing $25 \mathrm{~kg}$, the patient underwent reconstruction of bowel continuity, and discharged on the tenth postoperative day with normal bowel movements.

Retrospectively, after the first operation the patient admitted that four days earlier he had rapidly eaten and swallowed several mouthfuls of chicken meat without chewing and accidentally ingested a chicken bone.

\section{Discussion}

Foreign bodies (FB) accidentally ingested mostly pass through the gastrointestinal tract (GT) without any consequences [3]. The most common objects are dentures, fish bones, chicken bones, toothpicks, and cocktail sticks. Very small percentages perforate the GI tract, which may occur from mouth to anus. A definitive preoperative history of foreign body ingestion is uncertain [1].

Small bowel perforations by FB are rarely diagnosed preoperatively because clinical symptoms are usually nonspecific and mimic other surgical conditions, such as appendicitis and caecal diverticulitis [4]. Greater risk of perforation occurs at extreme ages, in those wearing dentures and orthodontic appliances [5], in patients with previous bowel pathology, or in alcoholic and psychiatric patients $[6,7]$.

The risk of perforation is related to the length and the sharpness of the object [8].

Overeating, rapid eating, or a voracious appetite may be contributing factors for ingesting chicken bones. The mean time from ingestion to perforation was 10.4 days [5]. Most perforations occur at the narrowing and angulations of the GI tract [9]. The most common abdominal site of perforation is the distal ileum [1,4,10-12], caecum, and left colon $[5,11,13,14]$, although an increased incidence of perforation has been reported in association with the Meckel diverticulum, the appendix, and/or mimicking diverticular disease $[2,10,15-17]$.

The clinical presentation includes peritonitis, abdominal abscess formation [2], perineum and scrotal abscess [18], enterovesical fistulas, intestinal obstructions, and hemorrhage [2]. The most common preoperative diagnoses were acute abdomen of uncertain origin [5]. Our patient had a clinical presentation of acute abdomen with a suspicion of perforated appendicitis. 
Patients with FB perforations in the stomach, duodenum, and large intestine were significantly more likely to be febrile, to have chronic symptoms, to have a normal total white blood cell count, and to be asymptomatic or present with an abdominal mass or abscess, compared to those with FB perforations in the jejunum and ileum [1].

The diagnosis was reached during laparotomy in more than $90 \%$ of the cases $[1,5,11,12]$. All cases had abdominal contamination and $66.7 \%$ had diffuse peritonitis [5].

Although the imaging of findings can be nonspecific, the identification of a chicken bone with an associated mass or extra luminal collection of gas in patients with clinical sign of peritonitis, mechanical bowel obstruction, or pneumoperitonem strongly suggests the diagnosis $[9,13,19,20]$.

The treatment usually involves resection of the bowel, although occasionally repair has been described [9]. The most common treatment was simple suture of the defect [11]. The lack of conditions pre-disposing accidental ingestion of FB and no specific history of FB are of interest in these cases [12].

During laparotomy we found diffuse fibro purulent peritonitis and adhesions. A tiny sharp-pointed object was found penetrating the inflamed portion of the distal ileum (Figure 2). Soon thereafter, a chicken wishbone was removed. We decided to do resection of the distal ileum and ileostomy, and four months later in the second operation we performed intestinal reconstruction. The postoperative treatment went well.

The HP diagnosis revealed that a macroscopic and histological feature of examined samples responds to Ileitis

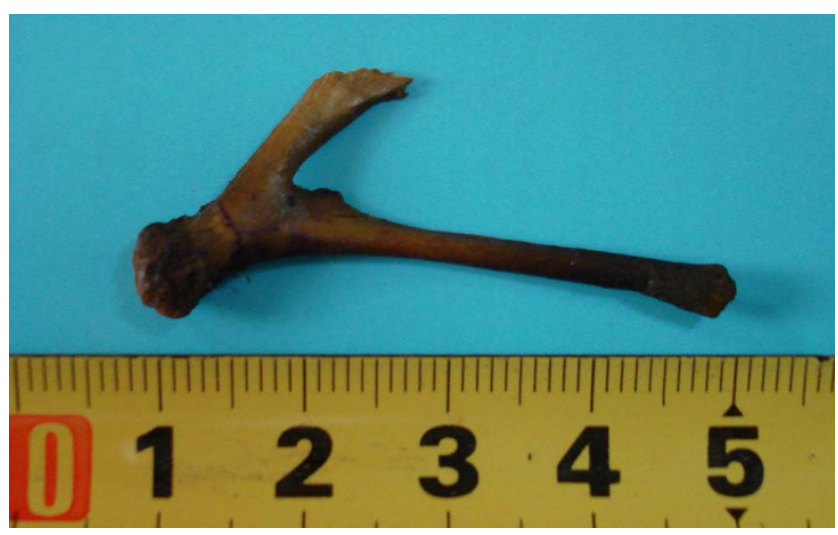

Figure 2

Extracted chicken wishbone from ileum. non specific, or the perforation of the small intestine (Figure 3).

\section{Conclusion}

Intestinal perforation by a chicken bone is rare and affects the left colon or distal ileum. The lack of information of ingestion and detection of chicken bones preoperatively are of interest to be considered in the differential diagnosis of acute abdomen, which in this case was treated surgically.

\section{Consent}

We have written consent form from the patient for publication of this case report and accompanying images.

\section{Competing interests}

The authors declare that they have no competing interests.

\section{Authors' contributions}

FTH, SHIH, DSK and SHMH performed the surgery and general anesthesia. HLGL and FK has made Histopathology. FTH and ASK made substantial contributions to the concept, design and definition of intellectual content along with the literature search of the manuscript. All authors have participated sufficiently in the work to take public responsibility for appropriate portions of the content.

All authors read and approved the final manuscript.

\section{References}

I. Goh BK, Chow PK, Quah HM, Ong HS, Eu KW, Ooi LL, Wong WK: Perforation of the gastrointestinal tract secondary to ingestion of foreign bodies. World J Surg 2006, 30(3):372-7.

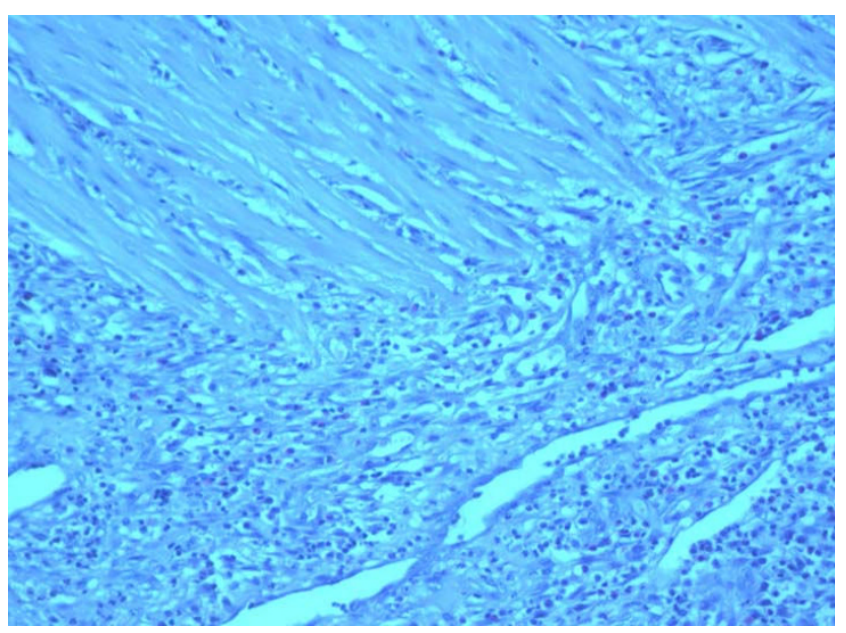

Figure 3

Disrupted smooth muscles replaced by granulation tissue. H\&E stained, $\times 10$. 
2. Akhtar S, McElvanna N, Gardiner KR, Irwin ST: Bowel perforation caused by swallowed chicken bones -a case series. Ulster Med J 2007, 76(I):37-38.

3. Waseem A, Madina $\mathrm{K}$ : Intestinal perforation due to an ingested foreign body. JCPSP 2007, I 7(4):234-235.

4. Yao CC, Yang CC, Liew SC, Lin CS: Small bowel perforation caused by a sharp bone: laparoscopic diagnosis and treatment. Surg Laparosc Endosc Percutan Tech 1999, 9(3):226-7.

5. Rodríguez-Hermosa JI, Codina-Cazador A, Sirvent JM, Martín A, Gironès J, Garsot E: Surgically treated perforations of the gastrointestinal tract caused by ingested foreign bodies. Colorectal Disease I 0(7):70I-707.

6. Ozel H, Topaloglu S, Yüksel BC, Avsar FM, Yildiz Y, Hengirmen S: Jejunal perforation in mentally retarded patient due to an ingested chicken bone. Hepatogastroenterology 2003, 50(Suppl 2):ccxxxviii-ccxxxix.

7. Velitchkov NG, Grigorov GI, Losanoff JE, Kjossev KT: Ingested Foreign Bodies of the Gastrointestinal Tract: Retrospective Analysis of 542 Cases. World J Surg 1005, 20:1001-1996.

8. Sarliève P, Delabrousse E, Michalakis D, Robert A, Guichard G, Kastler B: Multidetector CT diagnosis of jejunal perforation by a chicken bone. JBR-BTR 2004, 87:294-295.

9. Singh RP, Gardner JA: Perforation of the sigmoid colon by swallowed chicken bone: case reports and review of literature. Int Surg 1981, 66(2): 181-3.

10. McPherson RC, Karlan M, Williams RD: Foreign body perforation of the intestinal tract. Am J Surg 1957, 94(4):564-6.

II. Pinero Madrona A, Fernández Hernández JA, Carrasco Prats M, Riquelme Riquelme J, Parrila Paricio P: Intestinal perforation by foreign bodies. Eur J Surg 2000, I66(4):307-9.

12. Vasapollo L, Chiarot M, Gallinaro L, Papaspyropoulos V, Montesano G, Ciulli A, Bezzi M: Intestinal perforation caused by a chicken bone: apropos of a clinical case. Ann Ital Chir 1997, 68(4):555-8.

13. Rasheed AA, Deshpande V, Slanetz PJ: Colonic Perforation by Ingested Chicken Bone. AJR 200I, I 76:I 52.

14. Joglekar SP, Rajput I, Kamat S, Downey SE: Sigmoid perforation caused by an ingested chicken bone presenting as right iliac fossa pain: a case report. Journal of Medical Case Reports [http:// www.jmedicalcasereports.com/imedial 208|40141720109| article.pdf?random $=33032]$.

15. Gómez N, Roldós F, Andrade R: Intestinal perforation caused by chicken bone mimicking perforated colonic diverticulitis. Acta Gastroenterol Latinoam 1997, 27(5):329-30.

16. Gregorie $\mathrm{HB}$ Jr, Herbert $\mathrm{KH}$ : Foreign body perforation of Meckel's diverticulum. Am Surg 1967, 33(3):23 I-3.

17. Chan KW: Perforation of Meckel's diverticulum caused by a chicken bone: a case report. Journal of Medical CaseReports [http:/ /www.jmedicalcasereports.com/imedia/ |465682072|83855 article.pdf?random $=824785$ ]

18. Moreira CA, Wongpakdee S, Gennaro AR: A Foreign Body (Chicken Bone) in the Rectum Causing Extensive Perirectal and Scrotal Abscess: Report of a Case. Dis Colon Rectum 1975, I 8(5):407-409.

19. Maglinte DD, Taylor SD, Ng AC: Gastrointestinal perforation by chicken bones. Radiology 1979, I30(3):597-9.

20. Yeung KW, Chang MS, Hsiao CP, Huang JF: $C$ T evaluation of gastrointestinal tract perforation. Clinical Imaging 2004 28(5):329-333.
Publish with Bio Med Central and every scientist can read your work free of charge

"BioMed Central will be the most significant development for disseminating the results of biomedical research in our lifetime. "

Sir Paul Nurse, Cancer Research UK

Your research papers will be:

- available free of charge to the entire biomedical community

- peer reviewed and published immediately upon acceptance

- cited in PubMed and archived on PubMed Central

- yours - you keep the copyright
BioMedcentral 